\title{
Interaction of Mechanical Heterogeneity and Residual Stress on Mechanical Field at Crack Tips in DMWJs
}

\author{
Yubiao Zhang $\mathbb{D}^{\circ}$, He Xue $\mathbb{D}^{D}$, Shun Zhang, Shuai Wang ${ }^{\mathbb{D}}$, Yuman Sun $\mathbb{i D}^{\text {, }}$, Yonggang Zhang, \\ and Yongjie Yang
}

School of Mechanical Engineering, Xi'an University of Science and Technology, Xi'an 710054, China

Correspondence should be addressed to He Xue; xuehe@xust.edu.cn

Received 23 November 2021; Revised 31 January 2022; Accepted 2 February 2022; Published 26 February 2022

Academic Editor: Jariah Mohamad Juoi

Copyright (c) 2022 Yubiao Zhang et al. This is an open access article distributed under the Creative Commons Attribution License, which permits unrestricted use, distribution, and reproduction in any medium, provided the original work is properly cited.

\begin{abstract}
The interaction between the mechanical heterogeneity and the residual stress in dissimilar metal welded joints (DMWJs) leads to a complex mechanical field of crack tips, which strongly affects stress corrosion cracking (SCC) behaviors. A dual-field coupling model was established by using the user-defined field (USDFLD) and the predefined stress field method based on the elastoplastic finite element method in this study. Thus, the mechanical heterogeneity and the residual stress of the DMWJ are realized. The influence of the interaction between the mechanical heterogeneity and the residual stress on the mechanical field of crack tips at different locations was investigated. The results show that the mechanical heterogeneity causes the stress and strain distribution on both sides of the crack tip asymmetry. And the residual stress affects the magnitude of the stress and strain around the crack tip. The variation trend of the stress and strain along the crack propagation with crack length is basically the same as that of the residual stress. However, the stress and strain distributions are slightly lagging behind the residual stress distribution due to the redistribution of the residual stress caused by the crack propagation. In addition, the stress and strain range of cracks at different positions with crack length are also different.
\end{abstract}

\section{Introduction}

With the development of structural integrity assessment, more and more attention has been paid to the research on crack-like defects in important mechanical structures (nuclear power, aviation, transportation, etc.). It is one of the most important issues in the world to reach or even prolong the service life of the structures with defects. Considering that the service equipment is often subjected to a harsh service environment in actual operation, and it is very easy to produce "low stress" failure below the design load. Stress corrosion cracking (SCC) caused by the water environment, susceptible materials, and the internal and external load will seriously affect the safe operation and service life of mechanical structures [1-4]. Dissimilar metal welded joints (DMWJs) are widely present in connection parts with different materials. And the DMWJ is the weakest link that is most likely to generate SCC because the welding process will cause the nonuniform distribution of the local microstructure and material mechanical properties and inevitably induce the residual stress [5-7]. Both will significantly affect the stress and strain field at the crack tip of the DMWJ, which is one of the main factors affecting SCC behaviors [8-10]. In particular, the SCC behavior is more unpredictable under the interaction of the mechanical heterogeneity and the residual stress. Therefore, it is of great significance to study the mechanical field at the crack tip in the DMWJ under the interaction of the mechanical heterogeneity and the residual stress in detail.

The heterogeneity of mechanical properties mainly includes the heterogeneity of yield strength and strain hardening exponent. Recent research found that the distribution of the mechanical properties in DMWJs is very nonuniform through the tests of mini-sized flat tensile specimens. Especially, there are continuous changes of the mechanical properties in the softening and hardening zone near the material interface, thus the interface area between two materials cannot be ignored [11]. And the stress and strain at 
the crack tip vary with the difference of the mechanical properties when the crack is located in different material regions [12]. However, the DMWJ was simplified to a "Sandwich" model when studying SCC behaviors in most previous studies $[10,13,14]$. A sudden change in the mechanical properties at the material interface is produced, and it cannot accurately describe the mechanical heterogeneity of the DMWJ. Thus, structural integrity assessment has certain limitations by using the "Sandwich" model [15-17]. More detailed characterization of the DWMJ mechanical properties will greatly help the research of the crack tip mechanical field. In addition to the mechanical heterogeneity, the residual stress of the DMWJ also has a significant influence on the mechanical field of the crack tip, and it is the dominant driving force affecting SCC behaviors [18-21]. Some scholars found that the residual stress will noticeably change the stress and plastic strain of the crack tip, and the residual stress is redistributed on account of the crack propagation, which results in the mechanical field of the crack tip becoming more complex [22-24]. Substantial studies have shown that the distribution of the residual stress is nonuniform along the weld seam direction. Furthermore, sometimes, the residual stress might exceed the yield strength of the base metal and the weld metal $[25,26]$. And the residual stress of the DMWJ is more of a concern for SCC than the working load [27-30]. However, the influence of the interaction between the mechanical heterogeneity and the residual stress on the crack tip mechanical field is unclear.

It is necessary for predicting SCC behaviors to more accurately characterize the local mechanical properties of materials and consider the role of the residual stress. In this study, a continuous transition model of the mechanical properties was established by the user-defined field (USDFLD) in ABAQUS, and the residual stress was applied by the predefined stress field method. The model of dualfield coupling is thus established. Then, the influence of interaction between the mechanical heterogeneity and the residual stress on the mechanical field of cracks with different lengths was investigated through the submodel technique in detail, which provides a new numerical calculation method for the safety assessment and life prediction in engineering practice.

\section{Calculation Procedures}

2.1. Geometric Model and Materials. In order to study the influence of the interaction between mechanical properties heterogeneity and residual stress on the mechanical field at the crack tip, this study selected the DMWJ, which connects the safe-end piping to the nozzle of the reactor pressure vessel (RPV) in the primary circuit of pressurized water reactors (PWRs) as the research object, as shown in Figure 1(a). The DMWJ is simplified to a two-dimensional plane strain model in the finite element analysis according to the geometric structure of the DMWJ, and the sampling position of the numerical simulation is shown in Figure 1(b). The sampling length of the DMWJ is $160 \mathrm{~mm}$, which is composed of the base metal (austenitic stainless steel $316 \mathrm{~L}$ and low-alloy steel SA508), the weld metal (Alloy52Mw), the buttering layer (Alloy52Mb), and the cladding layer (308/ 309L), respectively. The sample geometric dimensions and crack positions are shown in Figure 1(c). Three characteristic locations were selected: Crack-1 was located in Alloy52 M, and Crack-2 and Crack-3 were, respectively, located in $316 \mathrm{~L}$ heat-affected zone (HAZ) and the interface of A508Alloy52Mb. The crack length a was set to $8-40 \mathrm{~mm}$, and nine lengths were evenly selected.

The stress-strain relationship of materials in the DMWJ is represented as the Ramberg-Osgood equation, which is written as

$$
\frac{\varepsilon}{\varepsilon_{0}}=\frac{\sigma}{\sigma_{y}}+\alpha\left(\frac{\sigma}{\sigma_{y}}\right)^{n}
$$

where $\sigma$ is the true stress, $\varepsilon$ is the true strain, $\sigma_{y}$ is the yield stress, $\varepsilon_{y}$ is the yield strain, $\varepsilon_{0}=\sigma_{y} / E, E$ is elastic modulus, $\alpha$ is the offset coefficient, and $n$ is the strain hardening exponent. Generally, the elastic modulus of the materials is $193000 \mathrm{MPa}$, and Poisson's ratio is 0.288 in the DMWJ, and these two parameters are considered to be constant in physical experiments and numerical simulations [24]. To characterize the mechanical properties of the DMWJ more accurately, including the yield strength and the strain hardening exponent of materials, the Vickers hardness $\mathrm{HV}$ of different regions in the DMWJ was obtained through the Vickers hardness experiment in this study. Then, the yield strength and the strain hardening exponent of the DMWJ were calculated by the theoretical formulas. The sample of the DMWJ used in the experiment is shown in Figure 2(a). The experiment was completed at room temperature, and the indentation morphology of the sample is shown in Figure 2(b).

Figure 3 shows the distribution of Vickers hardness and the yield strength distribution in the DMWJ through the experiment. The yield strength of two base metals and their HAZ can be obtained according to (2) [31]:

$$
\sigma_{y}=3.28 \mathrm{HV}-221 \text {. }
$$

The yield strength of weld metal Alloy52M can be obtained according to (3) [31]:

$$
\sigma_{y}=3.15 \mathrm{HV}-168
$$

And the strain hardening exponent $n$ can be obtained according to (4) [32]:

$$
n=\frac{1}{\kappa \ln \left(1390 / \sigma_{0}\right)},
$$

where $\kappa=0.163$. It is obvious from Figure 3 that welding causes changes in mechanical properties, especially in HAZ. In ABAQUS, the continuous transition model of mechanical properties was established by USDFLD to characterize the mechanical heterogeneity [15].

2.2. Residual Stress Model. According to the experiments conducted by researchers of Mitsubishi in Japan, the residual stress distribution of the DMWJ at the safe-end of nuclear power plants was obtained, including axial and hoop [33]. 


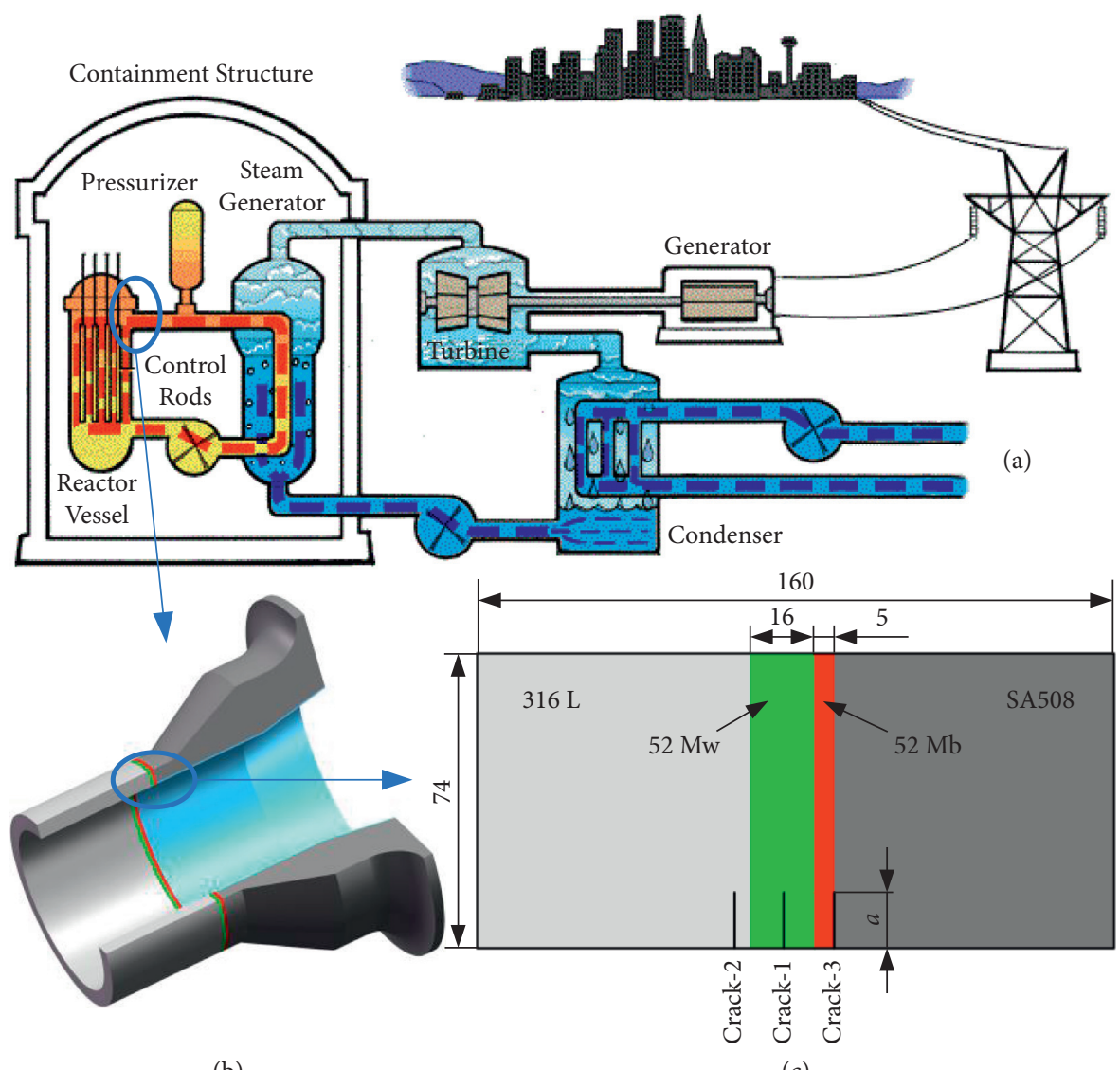

(b)

(c)

Figure 1: DMWJ which connects safe-end piping to nozzle of reactor pressure vessel. (a) Pressurized water reactor, (b) DMWJ and sampling position, (c) sample geometric dimensions and three characteristic cracks $(\mathrm{mm})$.

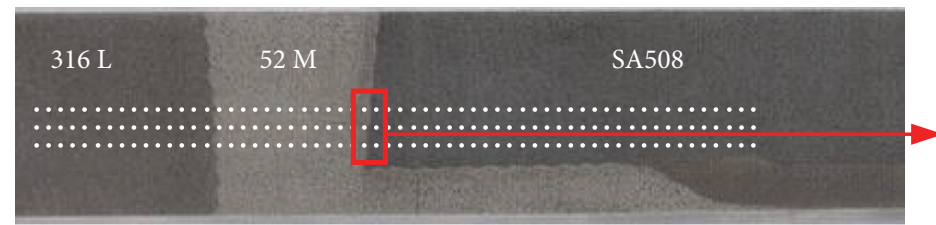

(a)

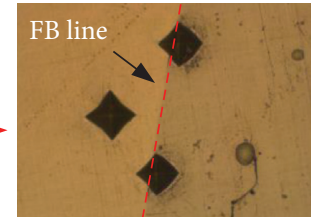

(b)

Figure 2: Vickers hardness experiment. (a) Experimental sample and hardness test point, (b) indentation morphology of sample.

Because SCC in DMWJs usually appears on the inner surface of the piping and cracks along the radial direction, the effect of the axial residual stress on crack is more critical than that of the hoop residual stress. Only the axial residual stress is considered in the finite element analysis in this study. Figure 4 shows the axial residual stress distribution. It can be seen that the variation of residual stress is very nonuniform. The residual stress is applied by the predefined stress field method in this study to obtain the most accurate residual stress [20].

2.3. Finite Element Model. The submodel technique was used to obtain the stress and strain field accurately, and the submodel was a circle with a radius of $0.1 \mathrm{~mm}$ around the crack tip in finite element analyses. $2 \mathrm{D}$ plane strain eight-node isoperimetric elements (CPE8) were adopted in both the global model and submodel. Figure 5(a) shows the global model and boundary settings of Crack-1 with $a=8 \mathrm{~mm}$. The $X$-direction of the left and right boundaries of the global model was fixed, and the boundary of the submodel was driven by the calculation results of the global model. The mesh number of the global model and the submodel were 4122 and 2320, respectively. The crack propagation direction and the circle around the crack tip can be adopted as characteristic paths to observe better the distribution of the stress and strain around the crack tip $[15,24]$. In this study, Path-1 was extracted as a path from $-90^{\circ}$ to $90^{\circ}$ at a distance of $0.02 \mathrm{~mm}$ from the crack tip, and Path-2 was extracted as a path along the direction of crack propagation. The submodel and two paths are shown in Figure 5(b). 


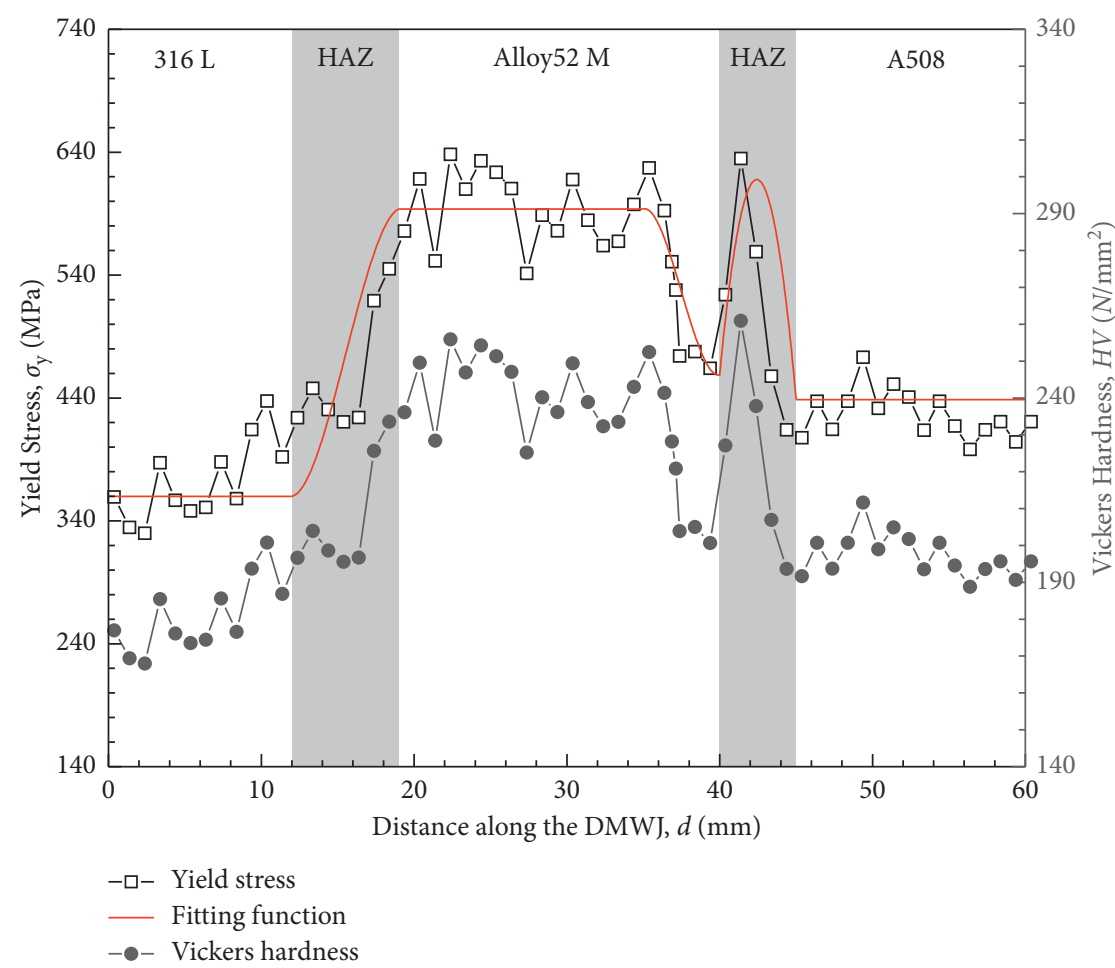

FIgURE 3: Material properties of DMWJ.
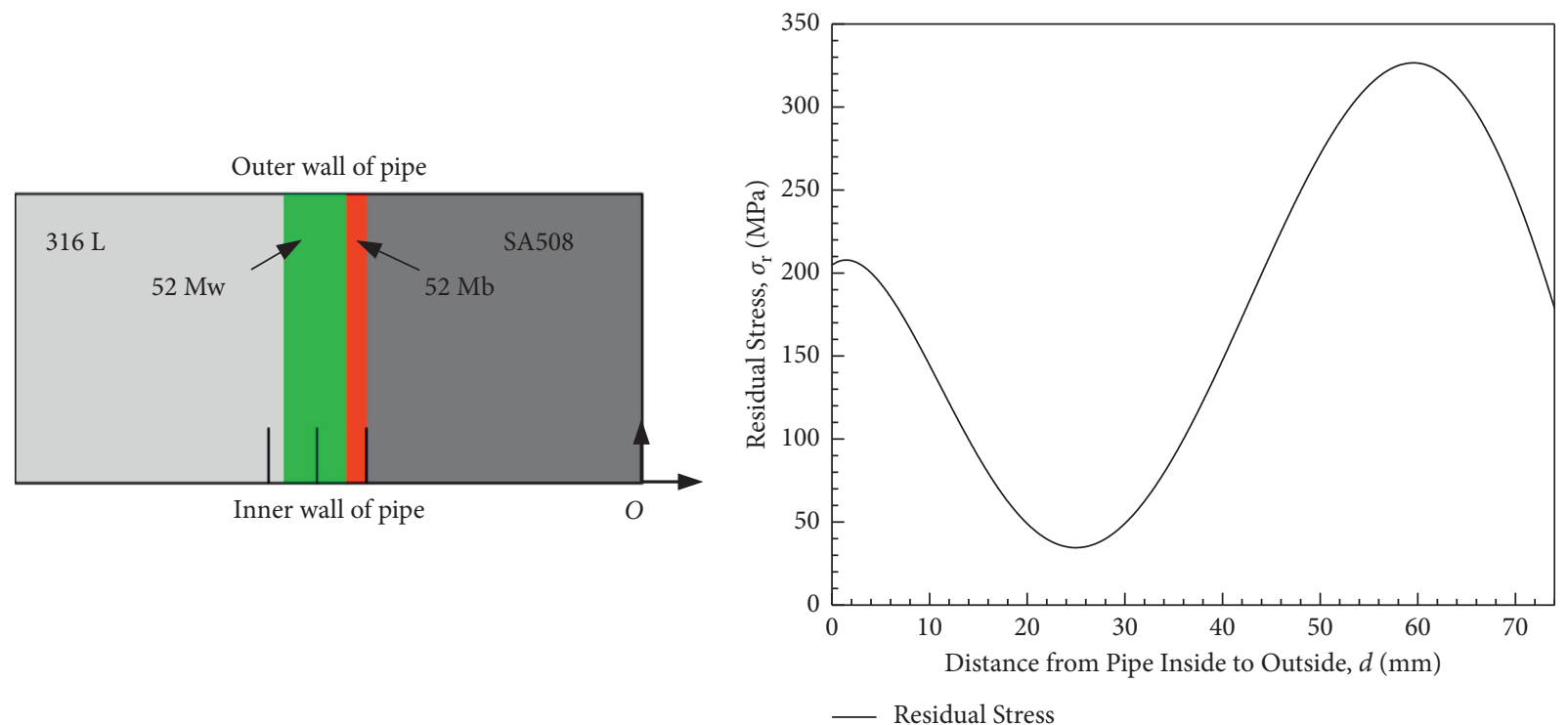

FIgURE 4: Axial residual stress distribution of DMWJ.

\section{Results and Discussions}

Figure 6 shows the yield strength distribution of the DMWJ through the USDFLD in ABAQUS. And the axial residual stress field of the DMWJ is shown in Figure 7. It clearly shows that the continuous transition of the mechanical properties is realized, and nonuniform residual stress is applied in numerical calculation.
3.1. Variation of the Stress and Strain along the Crack Propagation. The energy is released due to the initiation and propagation of the crack, which breaks the original selfbalanced state of the residual stress, and the residual stress is redistributed. To investigate the variation law of the residual stress redistribution with the crack length, the residual stress along Path-1 of Crack-1 with $a=8 \mathrm{~mm}, 16 \mathrm{~mm}, 24 \mathrm{~mm}$, $32 \mathrm{~mm}$, and $40 \mathrm{~mm}$ is shown in Figure 8. It can be seen that 


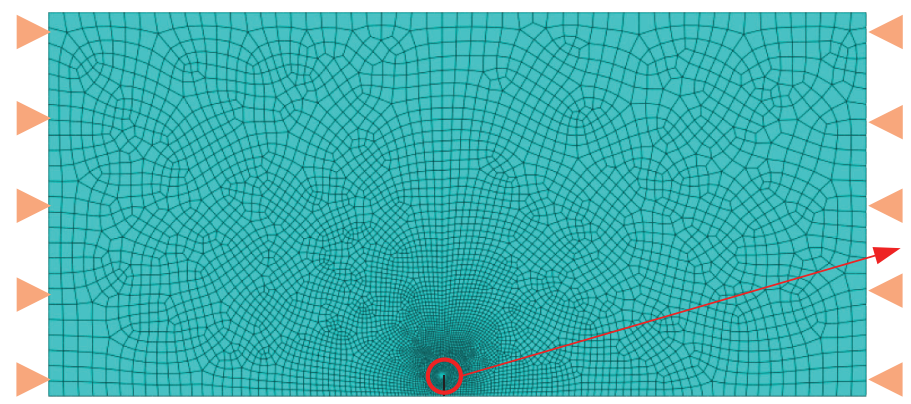

(a)

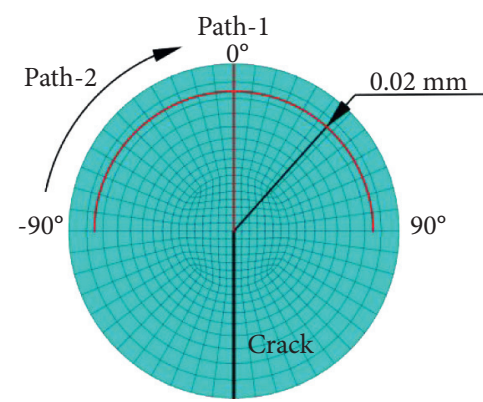

(b)

Figure 5: Finite element model in numerical simulation. (a) Global model, (b) submodel.
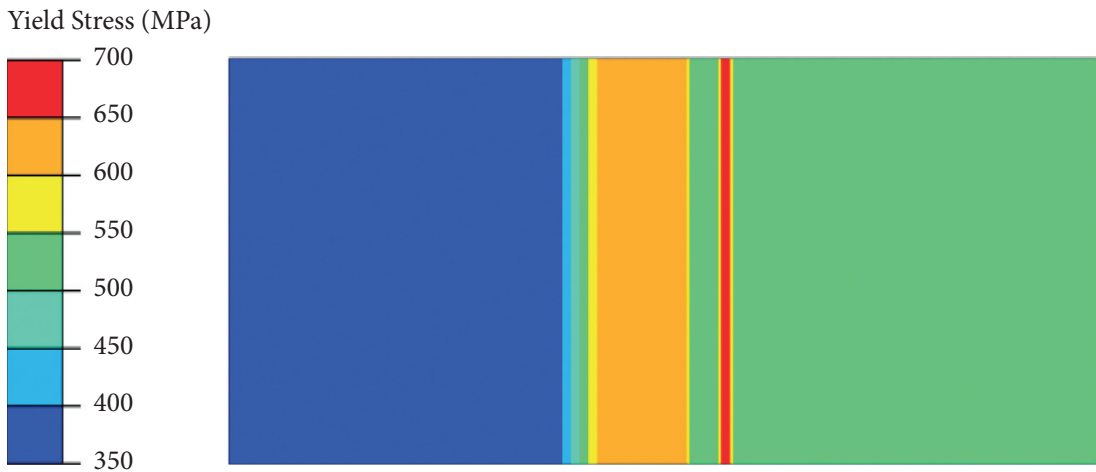

Figure 6: Yield strength distribution of DMWJ.

Residual Stress (MPa)
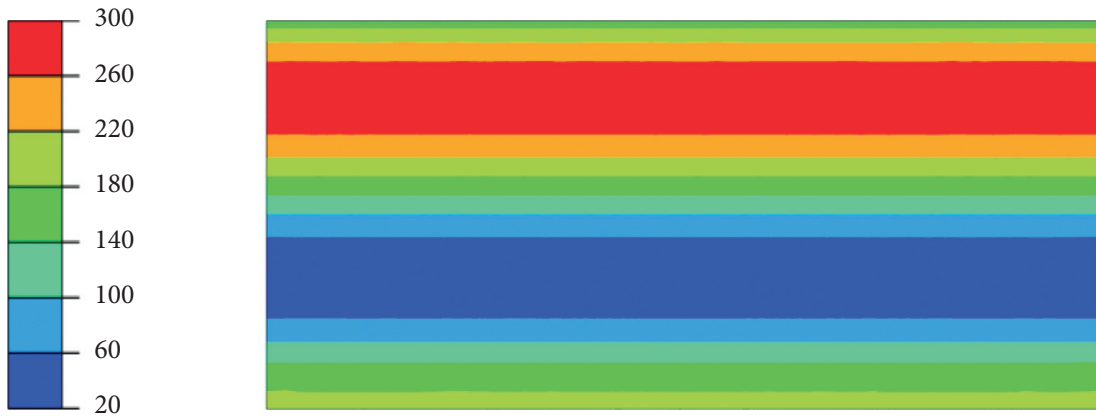

Figure 7: Axial residual stress field of DMWJ.

the crack propagation obviously leads to the redistribution of the residual stress. Especially, the redistribution of the residual stress is more apparent when the crack length increases gradually. It should be noted that the residual stress valley value gradually increases and moves backward with the increase of the crack length, while the residual stress peak value decreases and moves slightly forward with the increase of the crack length. Hence, the residual stress redistribution leads to larger tensile stress around the crack tip than the original residual stress, which possibly provides a greater driving force than expected for the crack propagation. In addition, the residual stress near the outer wall decreases with the increase of the crack length. It indicates that the residual stress near the outer wall is significantly correlated with the crack length, and the crack propagation state may be obtained by the residual stress redistribution of the outer wall of the piping.

In order to investigate the variation law of the mechanical field around the crack tip of different lengths with residual stress distribution in more detail, the stress and strain along Path-1 of cracks at different positions with nine crack lengths were extracted and compared with the residual stress distribution. The distribution curves of the Von Mises stress and the tensile stress at $0.02 \mathrm{~mm}$ from crack tips on Path- 1 for cracks with different lengths are shown in Figures 9(a) and 9(b), respectively. The Mises stress and the tensile stress of Crack- 1 are much higher than the other two cracks under the same crack length condition. The stress will be bigger as the crack tip is located in the region of high residual strength. The variation trend of the stress with crack length is analogical for 


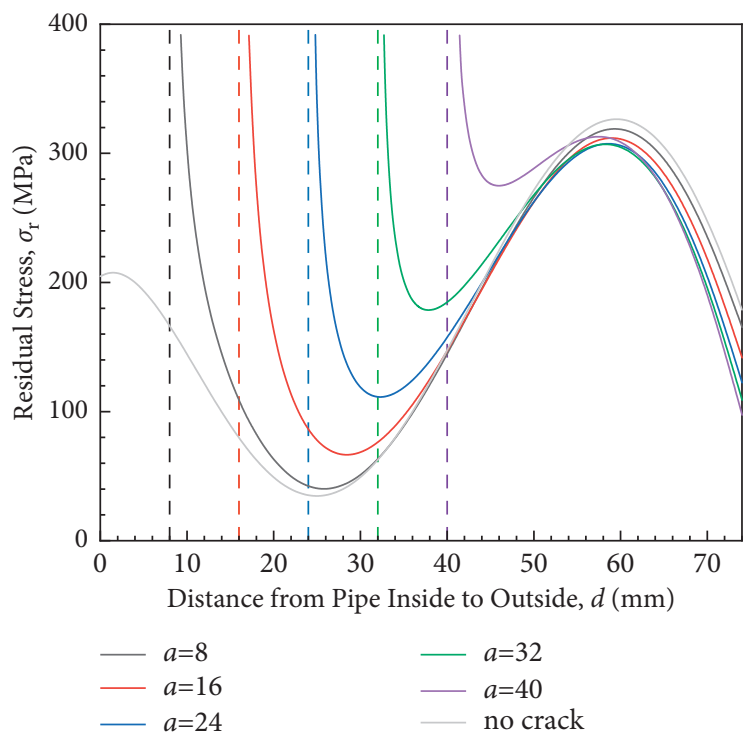

Figure 8: Residual stress of Crack-1 along Path-1.

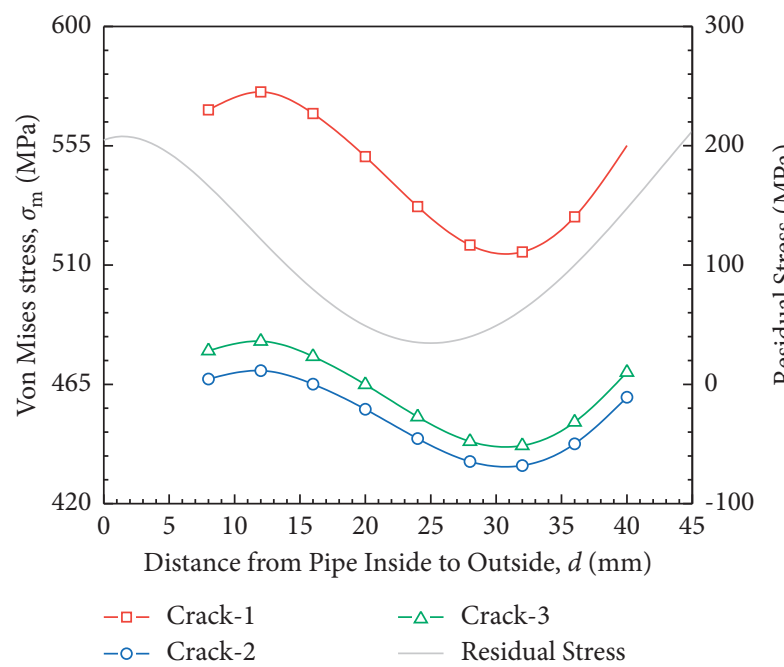

(a)

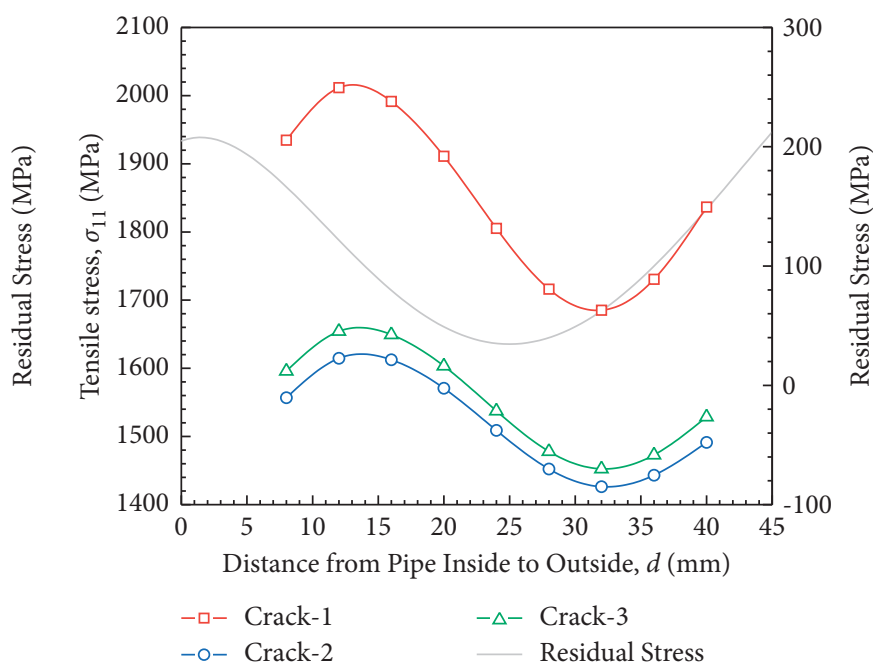

(b)

FIgURE 9: Distribution of the stress around the crack tip with crack length. (a) Von Mises stress, (b) tensile stress.

cracks at different locations. However, the variation amplitude of the crack tip stress of Crack- 1 is more severe than other positions of the crack, while the variation amplitude of the crack tip stress of Crack- 2 and Crack- 3 is relatively gentle. That is to say, there is a big gap between the maximum and the minimum on Crack-1 curve. This phenomenon is because Crack-1 is located in the weld metal, and the yield strength is larger. In other words, the greater yield strength of materials might induce the higher sensitivity of the stress at the crack tip to the residual stress. By comparing the residual stress distribution, it should be noted that the peak and valley values of the stress separately lag behind two extreme values of the residual stress distribution. This may be due to the redistribution of the residual stress. But the variation trend of the stress around the crack tip with the crack length is consistent with that of the residual stress.
According to the above research, the stresses in the highstress zone near the crack tip under the residual stress are larger than the yield strength corresponding positions, indicating the existence of the plastic zone at the crack tip. Figures 10(a) and 10(b) show the distribution curves of the equivalent plastic strain and tensile plastic strain around crack tip at $0.02 \mathrm{~mm}$ from crack tips on Path-1 for cracks with different lengths, respectively. Since Crack-1 is located in the weld metal Alloy52M with high yield strength and strain hardening exponent, the plastic strain around the crack tip of Crack-1 is significantly smaller than that of Crack-2 and Crack-3, which is opposite to the crack tip stress. But the variation trend of the crack tip plastic strain at different positions with the crack length is analogical. Nevertheless, the variation amplitude of the crack tip plastic strain at three positions is diverse, and the variation 


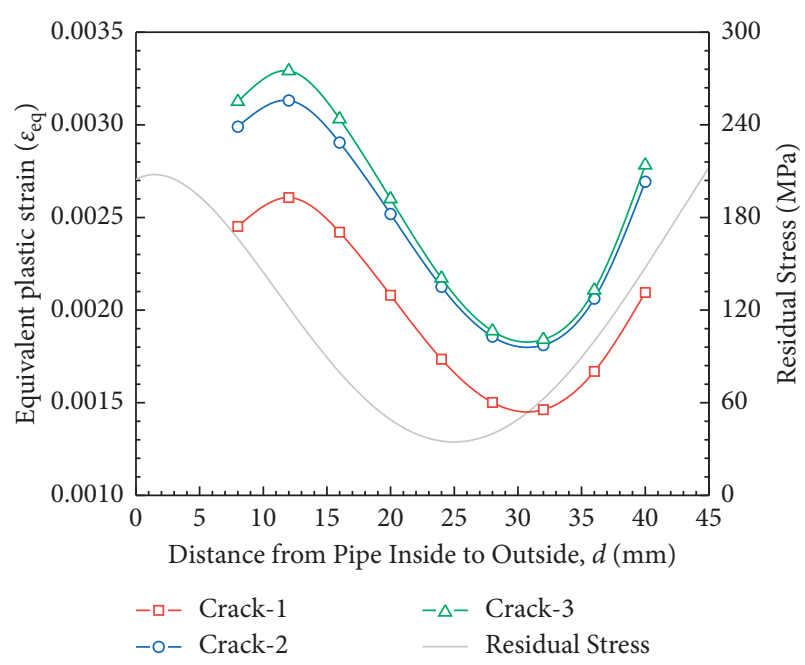

(a)

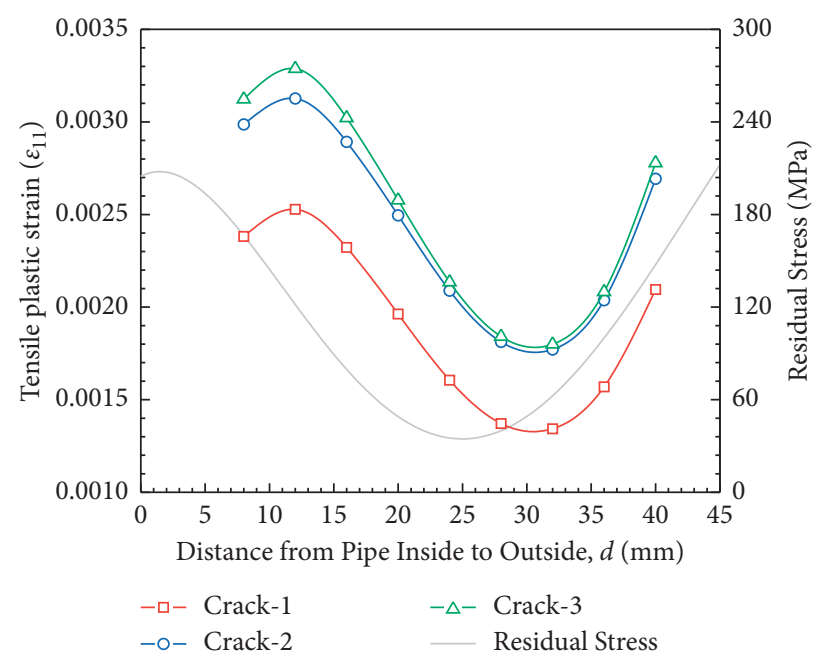

(b)

FIGURe 10: Distribution of the plastic strain around the crack tip with crack length. (a) Equivalent plastic strain, (b) tensile plastic strain.

amplitude of the crack tip plastic strain of Crack-3 is more severe. This phenomenon may be due to the fact that crack3 is located in an area with low yield strength, which results in a higher sensitivity of the crack tip plastic strain to the residual stress. The variation trend of the plastic strain is the same as the distribution of the axial residual stress but slightly lagging behind, and the residual stress noticeably affects the plastic strain around the crack tip.

3.2. Strain Field around the Crack Tip. Figure 11 shows the tensile plastic strain contours of three cracks with $a=40 \mathrm{~mm}$. It illustrates that the tensile plastic strain contour of Crack-1 is symmetrical. However, the tensile plastic strain contours of Crack- 2 and Crack-3 are asymmetrical. Combined with the mechanical heterogeneity, the yield strength and strain hardening exponent on the left side of the crack tip of Crack2 and Crack- 3 are obviously lower than that on the right side. Consequently, the tensile plastic strain on the left side of the crack tip is noticeably bigger than that on the right side. It indicates the mechanical heterogeneity has evidently an effect on the tensile plastic strain around the crack tip. The crack in HAZ of 316L may propagate to the base metal, while the crack in the A508-Alloy52 M interface may propagate to the weld metal. In other words, the crack may propagate to the region of larger tensile plastic strain. Experiments by some scholars have also confirmed this point: the propagation direction of cracks will be obviously changed by the mechanical heterogeneity caused by welding. Cracks located at or near the interface always deviate to the materials with lower strength $[34,35]$.

In order to investigate plastic strain near the crack tip of different lengths under the interaction of the mechanical heterogeneity and the residual stress in more detail, cracks with $a=8 \mathrm{~mm}, 16 \mathrm{~mm}, 24 \mathrm{~mm}, 32 \mathrm{~mm}$, and $40 \mathrm{~mm}$ are selected for analysis. The tensile plastic strain of three cracks along Path-1 is shown in Figure 12. It clearly shows that there is a high strain area near the crack tip, and the plastic strain decreases sharply as it is far from the crack tip. For the maximum and minimum of the tensile plastic strain when $a=8 \mathrm{~mm}$ and $a=32 \mathrm{~mm}$, respectively, and when $a=8 \mathrm{~mm}$ and $a=16 \mathrm{~mm}$, the tensile plastic strain is approximately the same. Compared with the residual stress distribution in Figure 4, the residual stress at $8 \mathrm{~mm}, 16 \mathrm{~mm}$, and $40 \mathrm{~mm}$ from the inner surface of the piping is bigger than that at $24 \mathrm{~mm}$ and $32 \mathrm{~mm}$. The tensile plastic strain of cracks with $a=8 \mathrm{~mm}, 16 \mathrm{~mm}$, and $40 \mathrm{~mm}$ is bigger, while the tensile plastic strain of cracks with $a=24 \mathrm{~mm}$ and $32 \mathrm{~mm}$ is smaller. It illustrates that the residual stress will obviously affect the magnitude of the stress and strain at the crack tip. The stress and strain at the crack tip do not simply increase with the increase of the crack length under the residual stress. Due to the redistribution of the residual stress, the degree of drop in the plastic strain at different crack tips is different, and the variation trend of the plastic strain lags behind that of the residual stress.

Figure 13(a) shows the tensile plastic strain of Crack-1 along Path-2. Since Crack-1 is located in weld metal Alloy52M, the local mechanical properties around the crack tip are almost identical, and the distribution of the tensile strain on both sides of the crack tip is symmetrical. The tensile plastic strains of Crack-2 and Crack-3 along Path-2 are shown in Figures 13(b) and 13(c), respectively. Crack-2 is located in the HAZ of $316 \mathrm{~L}$, and the yield strength and strain hardening exponent of the local area on the left side of the crack tip are lower. Crack-3 is located at the interface of A508-Alloy52Mb. Welding makes the local area of the base metal A508 appear high hardness, and the yield strength and strain hardening exponent in this area increase suddenly. For this reason, the tensile plastic strain on the left side of the crack tip is patently greater than that on the right side. However, it should be noted that the difference is smaller when $a=24 \mathrm{~mm}$ and $32 \mathrm{~mm}$. According to Figure 4, it is clear that the mechanical heterogeneity has a weak effect on the plastic strain around the crack tip under smaller residual stress. But bigger residual stress leads to greater tensile plastic strain and greater difference of the plastic strain on both sides of the crack tip. In other words, the asymmetrical 


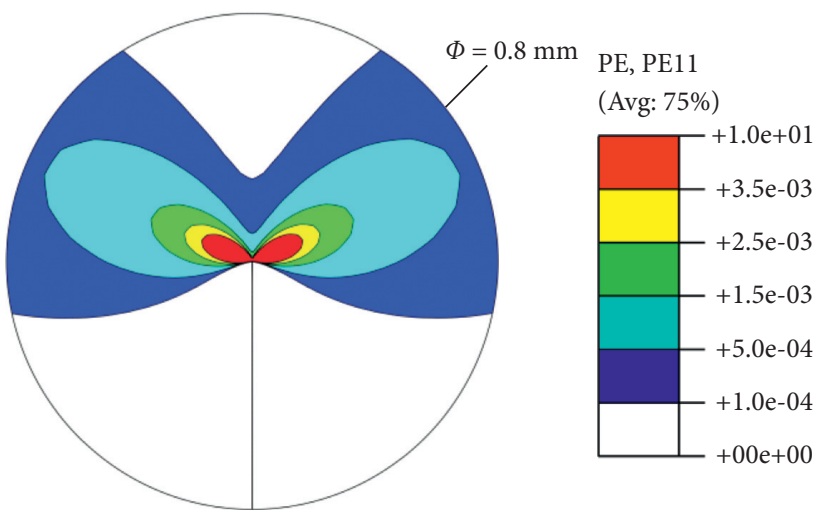

(a)

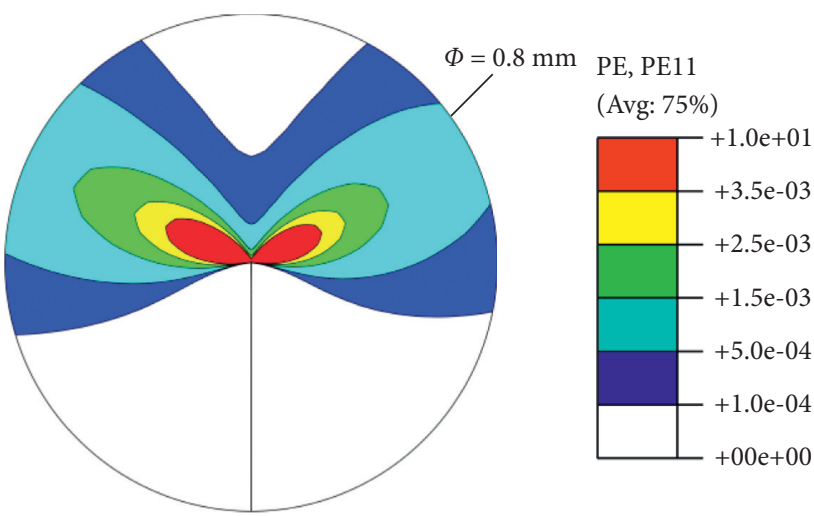

(b)

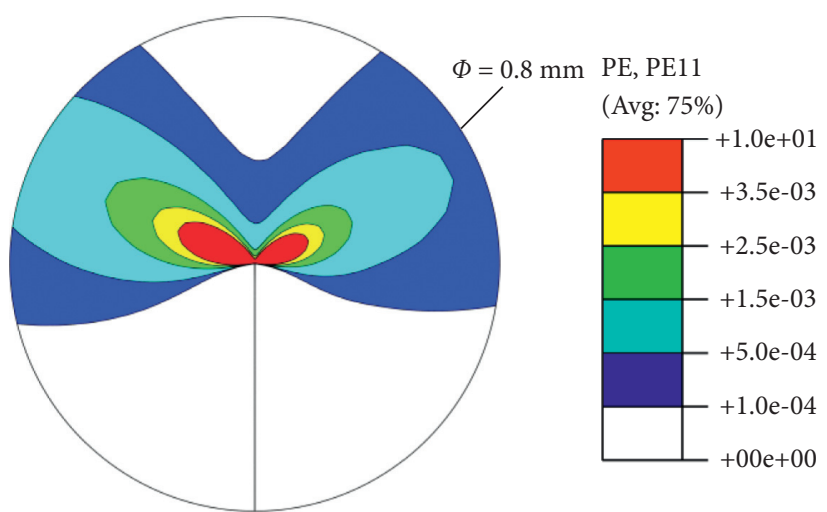

(c)

FIgURE 11: Tensile plastic strain contours of cracks with $a=40 \mathrm{~mm}$. (a) Crack-1, (b) Crack-2, (c) Crack-3.

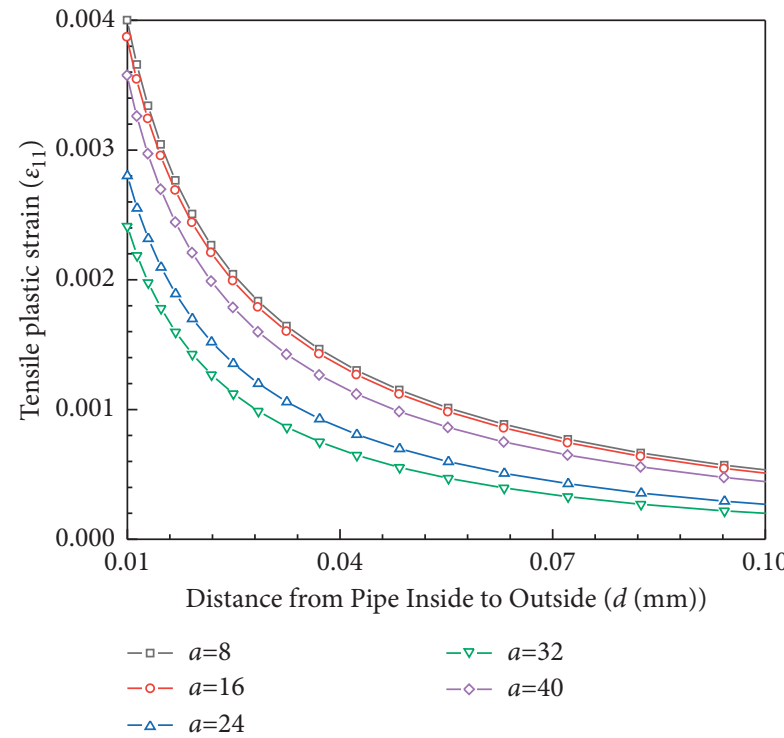

(a)

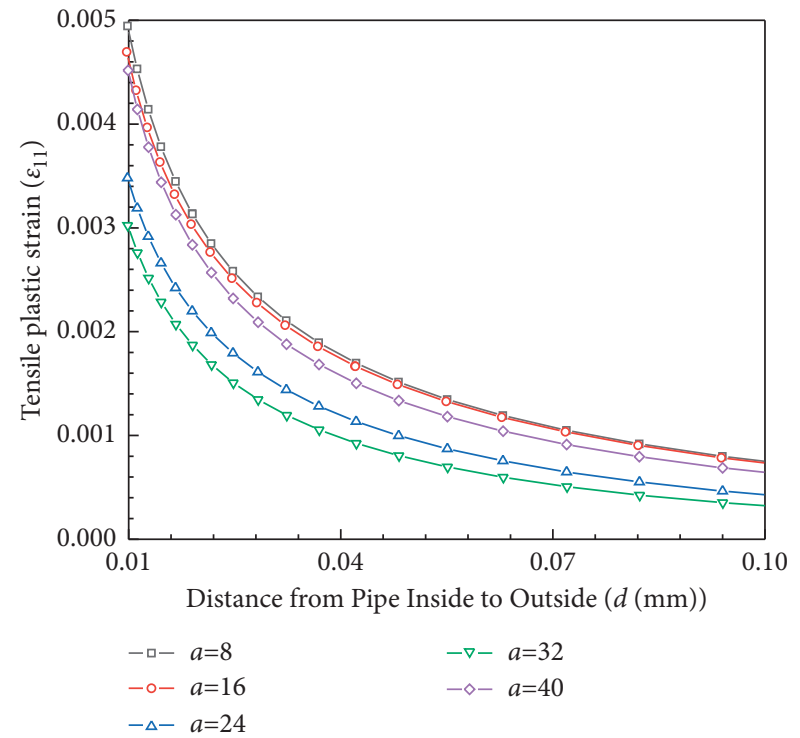

(b)

Figure 12: Continued. 


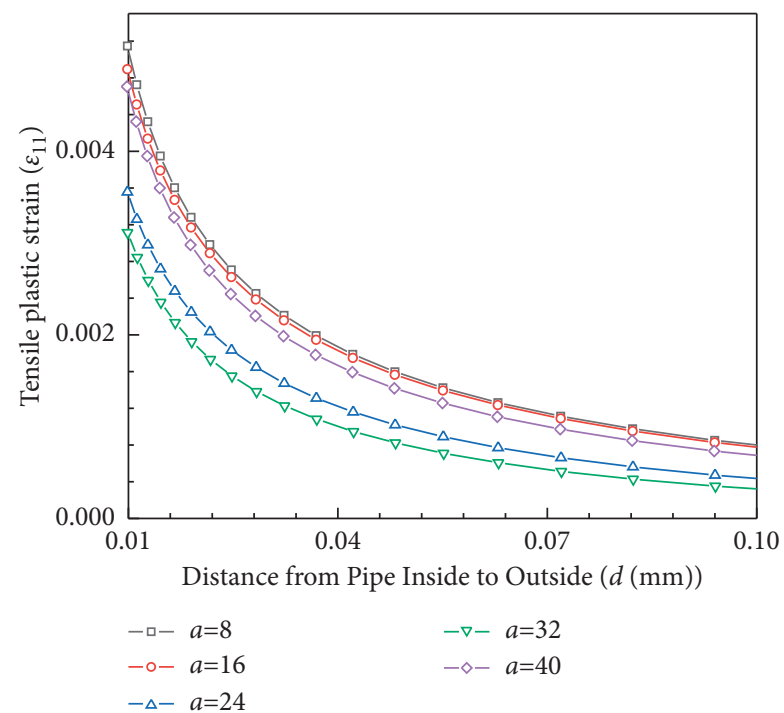

(c)

FIguRe 12: Tensile plastic strain along Path-1. (a) Crack-1, (b) Crack-2, and (c) Crack-3.

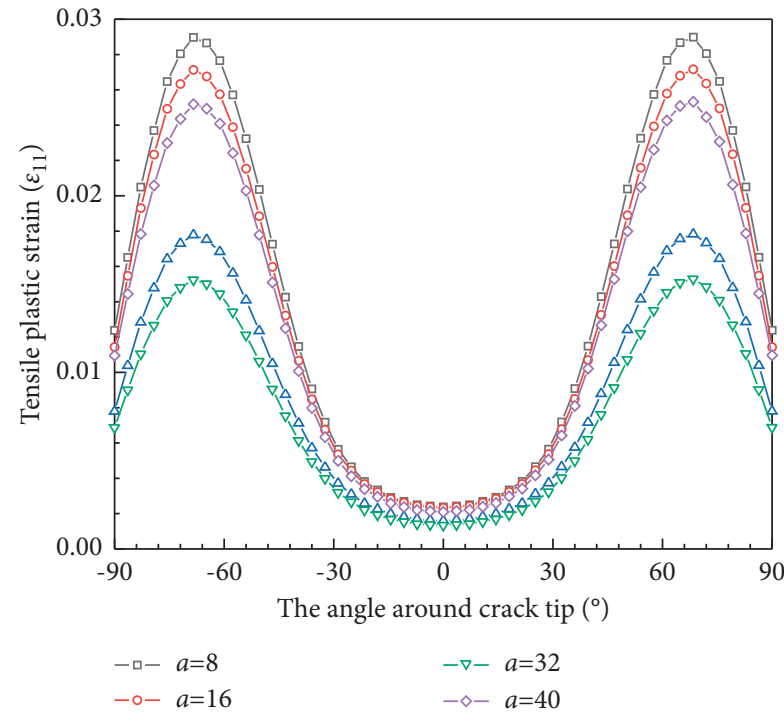

(a)

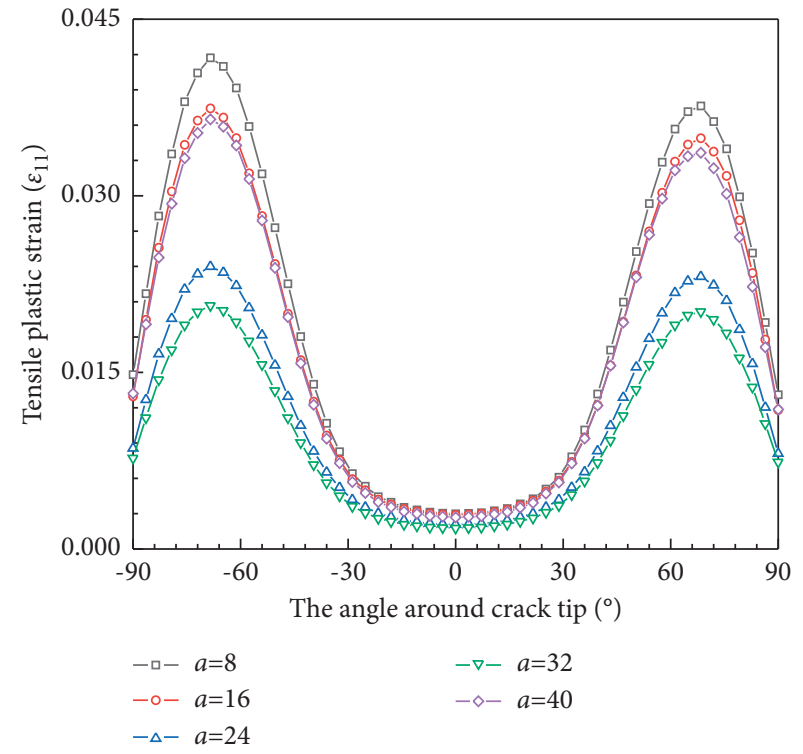

(b)

FIgURE 13: Continued. 


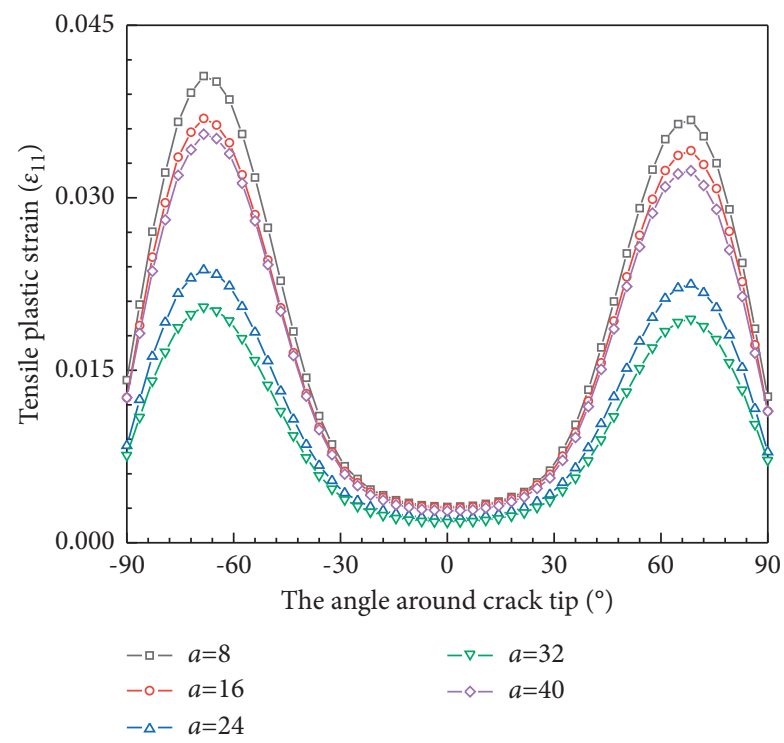

(c)

Figure 13: Tensile plastic strain along Path-2. (a) Crack-1, (b) Crack-2, (c) Crack-3.

effect of the mechanical heterogeneity on the stress and strain field at the crack tip is more pronounced. Larger residual stress promotes the effect of mechanical heterogeneity.

\section{Conclusion}

In this study, the dual-field coupling between the mechanical heterogeneity and the residual stress of the DMWJ is realized by USDFLD and the predefined stress field method. The mechanical field of cracks at three characteristic positions in the DMWJ under the interaction is investigated by the submodel technique. The main results are summarized as follows:

(1) The maximum of the residual stress decreases due to the residual stress redistribution. Conversely, the minimum of the residual stress increases. The variation trend of the crack tip stress and strain with crack length is basically consistent with that of the residual stress. However, the residual stress is redistributed due to cracks propagation, and the variation trend of the stress and strain at the crack tip with the crack length is slightly lagging behind that of the residual stress. Furthermore, the greater yield strength of materials might induce the higher sensitivity of the crack tip stress to the residual stress and reduce the sensitivity of the crack tip strain to the residual stress.

(2) A smaller crack tip stress in HAZ of 316L or A508alloy $52 \mathrm{M}$ interface: conversely, a larger crack tip stress exists in Alloy52 M, which provides a higher propagation driving force for cracks in the weld metal. Cracks located in the weld metal are more dangerous and worthy of concern.

(3) The plastic strain distribution on both sides of the crack tip is asymmetric because of the mechanical heterogeneity. The larger residual stress will result in a more prominent asymmetric effect of mechanical heterogeneity. Larger residual stress promotes the effect of mechanical heterogeneity, and the crack tends to propagate to the region of lower yield strength.

\section{Data Availability}

The data of interaction of mechanical heterogeneity and residual stress on mechanical field at crack tips used to support the findings of this study are included within the article.

\section{Conflicts of Interest}

The authors declare that they have no conflicts of interest.

\section{Acknowledgments}

This work was supported by the National Natural Science Foundation of China (52075434) and Natural Science Foundation of Shaanxi Provincial Department of Education (2021KW-36 and 2021JM-389).

\section{References}

[1] H. Hoffmeister and O. Klein, "Modeling of SCC initiation and propagation mechanisms in BWR environments," Nuclear Engineering and Design, vol. 241, no. 12, pp. 4893-4902, 2011.

[2] L. Zhao, J. Wang, H. Su, D. Du, L. Zhang, and S. Tu, "Stress corrosion cracking of the fusion boundary for 3041/82 dissimilar metal weld joint in simulated primary water," Corrosion, vol. 76, no. 2, pp. 176-187, 2020.

[3] H. Ming, R. Zhu, Z. Zhang et al., "Microstructure, local mechanical properties and stress corrosion cracking susceptibility of an SA508-52M-316LN safe-end dissimilar metal 
weld joint by GTAW," Materials Science and Engineering A, vol. 669, pp. 279-290, 2016.

[4] P. L. Andresen, "A brief history of environmental cracking in hot water," Corrosion, vol. 75, no. 3, pp. 240-253, 2019.

[5] D. Deng, K. Ogawa, S. Kiyoshima, N. Yanagida, and K. Saito, "Prediction of residual stresses in a dissimilar metal welded pipe with considering cladding, buttering and post weld heat treatment," Computational Materials Science, vol. 47, no. 2, pp. 398-408, 2009.

[6] Y. Ye, J. Cai, X. Jiang, D. Dai, and D. Deng, "Influence of groove type on welding-induced residual stress, deformation and width of sensitization region in a SUS304 steel butt welded joint," Advances in Engineering Software, vol. 86, pp. 39-48, 2015.

[7] J. Hou, Q. Peng, and T. Shoji, "Study of microstructure and stress corrosion cracking behavior in welding transition zone of Ni-based alloys," Jinshu Xuebao/Acta Metallurgica Sinica, vol. 46, no. 10, pp. 1258-1266, 2010.

[8] J. Ding, Z. Zhang, and J. Wang, "Micro-characterization of dissimilar metal weld joint for connecting pipe-nozzle to safeend in generation III nuclear power plant," Acta Metallurgica Sinica, vol. 51, no. 4, pp. 425-439, 2015.

[9] Y. P. Lei, Y. W. Shi, H. Murakawa, and Y. Luo, “The effect of mechanical heterogeneity and limit load of a weld joint with longitudinal weld crack on the J-integral and failure assessment curve," International Journal of Pressure Vessels and Piping, vol. 75, no. 8, pp. 625-632, 1998.

[10] H. Xue, K. Ogawa, and T. Shoji, "Effect of welded mechanical heterogeneity on local stress and strain ahead of stationary and growing crack tips," Nuclear Engineering and Design, vol. 239, no. 4, pp. 628-640, 2009.

[11] H. T. Wang, G. Z. Wang, F. Z. Xuan, C. J. Liu, and S. T. Tu, "Local mechanical properties and microstructures of Alloy52M dissimilar metal welded joint between A508 ferritic steel and 316L stainless steel," Advanced Materials Research, Trans Tech Publications Ltd, vol. 509, pp. 103-110, 2012.

[12] L. Zhao, H. Xue, and W. Tang, "Effect of welded mechanical heterogeneity on local stress and strain ahead of growing crack tips in the piping welds," Pressure Vessels and Piping Conference, vol. 44533, pp. 223-232, 2011.

[13] K. Fan, G. Z. Wang, S.-T. Tu, and F. Z. Xuan, "Effects of toughness mismatch on failure behavior of Bi-material interfaces," Procedia Engineering, vol. 130, pp. 754-762, 2015.

[14] L. Dong, Q. Peng, E.-H. Han, W. Ke, and L. Wang, "Microstructure and intergranular stress corrosion cracking susceptibility of a SA508-52M-316L dissimilar metal weld joint in primary water," Journal of Materials Science and Technology, vol. 34, no. 8, pp. 1281-1292, 2018.

[15] H. Xue, Y. Sun, and S. Zhang, "A numerical approach to analyze detail mechanical characteristic at the crack tip of SCC in dissimilar metal welded joints," Advances in Materials Science and Engineering, vol. 2021, Article ID 8429051, 12 pages, 2021.

[16] S. Geng, J. Sun, L. Guo, and H. Wang, "Evolution of microstructure and corrosion behavior in 2205 duplex stainless steel GTA-welding joint," Journal of Manufacturing Processes, vol. 19, pp. 32-37, 2015.

[17] H. Xue, Y. Bi, and S. Wang, "Compilation and application of UMAT for mechanical properties of heterogeneous metal welded joints in nuclear power materials," Advances in Materials Science and Engineering, vol. 2019, Article ID 3151823, 12 pages, 2019.

[18] S.-S. Kang, J.-S. Kim, and B.-Y. Lee, "The study for direct SCC fabrication in STS 304 pipe," Corrosion Engineering, Science and Technology, vol. 53, no. sup1, pp. 90-97, 2018.
[19] B. T. Lu, Z. K. Chen, J. L. Luo, B. M. Patchett, and Z. H. Xu, "Pitting and stress corrosion cracking behavior in welded austenitic stainless steel," Electrochimica Acta, vol. 50, no. 6, pp. 1391-1403, 2005.

[20] M. Mochizuki, "Control of welding residual stress for ensuring integrity against fatigue and stress-corrosion cracking," Nuclear Engineering and Design, vol. 237, no. 2, pp. 107-123, 2007.

[21] J.-Y. Nam, D.-h. Seo, S.-y. Lee, W.-K. Hwang, and B.-Y. Lee, "The effect of residual stress on the SCC using ANSYS," Procedia Engineering, vol. 10, pp. 2609-2614, 2011.

[22] R. Guo, H. Xue, and X. Gong, "Influence of residual stress and heterogeneity on mechanical field at crack tips in safety end of nuclear power plant," Procedia Structural Integrity, vol. 13, pp. 2202-2209, 2018.

[23] C. D. M. Liljedahl, M. E. Fitzpatrick, and L. Edwards, "Evolution of residual stresses with fatigue crack growth in integral structures with crack retarders," Materials Science and Engineering A, vol. 523, no. 1-2, pp. 152-159, 2009.

[24] A. R. Shahani, I. Shakeri, and C. D. Rans, "Effect of residual stress redistribution and weld reinforcement geometry on fatigue crack growth of butt welded joints," International Journal of Fatigue, vol. 139, Article ID 105780, 2020.

[25] W. Liang, H. Murakawa, and D. Deng, "Investigation of welding residual stress distribution in a thick-plate joint with an emphasis on the features near weld end-start," Materials \& Design, vol. 67, pp. 303-312, 2015.

[26] A. Contreras-Cuevas, J. Alamilla-López, R. Galván-Martínez, and O. Vega-Becerra, "The role of residual stresses in circumferential welding repairs of pipelines in SCC susceptibility," Materials Science Forum, Trans Tech Publications Ltd, vol. 793, pp. 159-168, 2014.

[27] P. Dong, "On the mechanics of residual stresses in girth welds," Journal of Pressure Vessel Technology, vol. 129, 2007.

[28] P. Ferro, F. Berto, and N. M. James, "Asymptotic residual stress distribution induced by multipass welding processes," International Journal of Fatigue, vol. 101, pp. 421-429, 2017.

[29] Y. Ren, A. Paradowska, and B. Wang, "Residual stress state of X65 pipeline girth welds before and after local and furnace post weld heat treatment," Journal of Pressure Vessel Technology, vol. 139, no. 4, 2017.

[30] T. Hayashi, S. F. Hankinson, and T. Saito, "Flaw evaluation for PWR and BWR component weld joints using advanced FEA modeling techniques," ASME Pressure Vessels and Piping Conference, vol. 43697, pp. 1125-1139, 2009.

[31] Y. Peng, C. Wu, J. Gan, and J. Dong, "Characterization of heterogeneous constitutive relationship of the welded joint based on the stress-hardness relationship using micro-hardness tests," Construction and Building Materials, vol. 202, pp. 37-45, 2019.

[32] Y. Ueda, Y. W. Shi, and S. Y. Sun, "Effects of crack depth and strength mismatching on the relation between J-integral and CTOD for welded tensile specimens," Transactions of JWRI, vol. 26, no. 2, pp. 133-140, 1997.

[33] I. Muroya, Y. Iwamoto, and N. Ogawa, "Residual stress evaluation of dissimilar weld joint using reactor vessel outlet nozzle mock-up model (report-1)," ASME Pressure Vessels and Piping Conference, vol. 48296, pp. 613-623, 2008.

[34] K. Fan, G. Z. Wang, F. Z. Xuan, and S. T. Tu, "Local failure behavior of a dissimilar metal interface region with mechanical heterogeneity," Engineering Failure Analysis, vol. 59, pp. 419-433, 2016.

[35] H. T. Wang, G. Z. Wang, F. Z. Xuan, and S. T. Tu, "An experimental investigation of local fracture resistance and crack growth paths in a dissimilar metal welded joint," Materials and Design, vol. 44, pp. 179-189, 2013. 